\title{
Cost Accounting Curriculum Related Competencies and Performance of Accountants in South Africa
}

\author{
Dolly Wanjau \\ Tshwane University of Technology, Faculty of Economics and Finance, Accounting Department, GaRankuwa Campus \\ wanjaudn@tut.ac.za
}

\author{
Doi:10.5901/mjss.2014.v5n25p108
}

\begin{abstract}
Purpose - Over the years, the context of work for accounting professionals has changed dramatically. In the present time, the accounting profession has witnessed the existence of a gap between the current and desired skills in the accounting field. The study intends to review the literature on the dynamic relationship between cost accounting curriculum content and performance of accountants in South Africa. Design- The paper used a desk study review methodology where relevant empirical literature was reviewed to identify main themes and to extract knowledge gaps. Findings - It was found that studies on the competence of cost accountants are few; the existing studies are not conclusive because they found either a positive relationship, negative relation or no significant relation at all. In addition, methodological gaps and contextual gaps exist since most studies are qualitative in nature and are from developing economies while few are from South Africa. This implies that this area has not been deeply explored thus paving the way for further research. Originality/value - The paper offers a guidance on classification of competencies acquired by cost accounting graduates and identifies a knowledge gap on to which further studies can be conducted. In addition, the paper results will have practical and policy implications as far as modeling curriculum development of cost accounting education is concerned.
\end{abstract}

Keywords: Performance of Accountants, Communication Competence, Problem solving Competence, Personal and Interpersonal Competencies, Information Technology Competencies, Modern Accounting Techniques.

\section{Background of Study}

Over the years, the context of work for accounting professionals has changed dramatically. Many practicing management accountants have moved to service the information needs of managers who have developed interests in sustainable business, stakeholder management, integrated reporting and a host of new techniques (Burns \& Vaivio, 2001; Scapens, 2006; Tan, Fowler \& Hawkes, 2004; Sharma, Lawrence \& Lowe, 2010). Tan, et al.(2004) point out that the cost accounting curriculum has not kept up with practice. What is being taught may not be relevant to a modern manufacturing environment. Bromwich (2010) observes that the nature and extent of the gap between college and practice raises questions generally about the role of cost accounting education in society. It is not surprising that concerns relating to how effectively academic research engages with practice have been voiced across a diverse range of practice based disciplines (Scapens \& Bromwich, 2010; Shapiro, Kirkman and Courtney, 2007; Van Helden \& Northcott, 2010). A range of new cost accounting techniques have emerged since the 1970s, for example, activity based costing, costs of quality reporting and strategic management accounting. However, while new techniques are being adopted in practice, the traditional management accounting concepts have not been completely abandoned (Tan et al., 2004).

Armitage, Bryant, Dunnill, Hayes, Hudson, Kent, Lawes and Renwick (2003) describe curriculum as all about finding out if our new course is working properly. It involves generating data through a process of enquiry and then, on the basis of this, making judgements about the strengths and weaknesses and the overall effectiveness of the course, and making decisions about how to improve it further. Neary (2002) states that teachers and lecturers often spend many hours carefully considering course aims, learning objectives, learning outcomes, competencies to be achieved, teaching, learning and assessment strategies, but fail to evaluate the effectiveness of the curriculum. Addressing the curriculum content of the specific topics being assessed is essential in researching factors that affect student achievement. According to Arora (2010) having topics in the curriculum and teaching them to students is very important.

\section{Objectives of the Study}

The major objective of the paper will be to analyze the effect of cost accounting curriculum related competencies on the 
performance of accountants in South Africa.

The specific objectives will be;

1) To establish the effect of communication competence on the performance of accountants in South Africa

2) To examine whether problem solving competence affects the performance of accountants in South Africa

3) To investigate whether personal and interpersonal competence affects the performance of accountants in South Africa

4) To determine whether information technology competence affects the performance of accountants in South Africa

5) To establish whether competence in modern accounting techniques affects the performance of accountants in South Africa

\section{Justification of the Study}

The study will be of benefit to the universities' administrators and educators in South Africa to revisit the curriculum to identify the dynamics and shortcomings. The study will also benefit the accounting examination body in South Africa to identify gaps in the curriculum and correct the same to ensure updated and acceptable standards of curriculum content.

Furthermore, the study will also benefit South African Institute of Charted Accountants (SAICA) to identify training needs among the accounting professionals and facilitate the same to ensure improved performance among the accountants. They will also use the findings of the study to formulate viable policy documents that effectively boost productivity among professionals of accountancy. These may relate to regulating those aspects that threaten to adversely impact on the accounting operations and development of such organizations.

Additionally the findings of this study will enrich existing knowledge by adding to the pool of information available about the topic under study. Hence, it will be of interest to both researchers and academicians who seek to explore and carry out further investigations. It will provide a basis for further research since it has not covered all the technical and non- technical factors that affect accountants' performance such as remuneration and the work environment.

\section{Literature Review}

This section provides the theory that underpins the study as well as the general and empirical literature that supports the objectives of the study.

The theory that supports this study is the theory of competence which is discussed herein.

\section{Theory of Competence}

Initially, this theory was described as "Four Stages for Learning Any New Skill". The theory was developed at the Gordon Training International by its employee Noel Burch in the 1970s. It has since been frequently attributed to Abraham Maslow, although the model does not appear in his major works. It suggests that individuals are initially unaware of how little they know, or unconscious of their incompetence. As they discover their incompetence, they consciously acquire a skill and then consciously use it. Eventually, the skill can be utilized without it being consciously thought through, the individual is said to have then acquired unconscious competence. Several elements, including helping someone know what they do not know or recognise a blind spot, can be compared to some elements of a Johari window, although Johari deals with self-awareness, while the four stages of competence deals with learning stages (Flower, 1999).

According to Flower (1999) and Process Coaching Centre (2001), the four stages include; unconscious incompetence where the individual does not understand or know how to do something and does not necessarily recognise the deficit. They may deny the usefulness of the skill. The individual must recognise their own incompetence, and the value of the new skill, before moving on to the next stage. The length of time an individual spends on this stage depends on the strength of the stimulus to learn. Conscious incompetence is where even though the individual does not understand or know how to do something, he or she does recognize the deficit, as well as the value of a new skill in addressing the deficit. The making of mistakes can be integral to the learning process at this stage. Conscious competence is where the individual understands or knows how to do something. However, demonstrating the skill or knowledge requires concentration. It may be broken down into steps, and there is heavy conscious involvement in executing the new skill. Unconscious competence is when the individual has had so much practice with a skill that it has become "second nature" and can be performed easily. As a result, the skill can be performed while executing another task. The individual may be able to teach it to others, depending upon how and when it was learned (Flower, 1999). This 
theory is relevant to the study as it describes the various competences types and its applicability in real life situations required for cost accountants.

\section{Empirical Review}

This section provides the discussion of the general and empirical literature of the studies, which are done according to the objectives of this study.

\subsection{Communication Competence and Performance}

Clare, Gardner, Stringer and Rosalind (2003) investigate the impacts of curriculum on students' levels of communication apprehension. An emerging concern in accounting is that attempts made to improve students' communication skills may fail or be less effective for some students because such attempts do not improve, or may even exacerbate students' anxiety about communicating, which in turn leads to poorer performance. The results from this study show that students in their final year of study who are exposed to greater communication demands, do not on average have higher levels of communication apprehension than their peers in earlier studies. The levels of communication apprehension for final year students decline most evidently for those students starting with higher average levels of apprehension.

De Villiers, (2010) explored the changing needs of employers and the business community in relation to the balance between technical and soft skills, such as communication skills, business presentation skills and other interpersonal skills. The objective of this study was to identify the importance of soft relational skills for all business graduates, including accountants. Results showed that soft skills not only distinguish outstanding leaders and managers, but can also be positively linked to strong performance at all other levels of professionals.

Accounting professionals are called upon to communicate financial and non-financial information so that it is understood by individuals with diverse capabilities and interests. Individuals entering the accounting profession should have the skills necessary to give and exchange information within a meaningful context and with appropriate delivery. They should have the ability to listen, deliver powerful presentations and produce examples of effective business writing (Opt \& Loffredo, 2000). Hassall's (2000) study also indicates that prior educational background (science-based, artsbased, or a mix) is significantly associated with average levels of written communication apprehension for accounting and business majors, with those from a science background being highest and those from an arts background being lowest. Students' self-ratings of their own academic ability are also found to be significantly associated with average levels of communication apprehension for both writing and oral communicating, with those students reporting higher than average ability having lower than average levels of communication apprehension.

Marriott, Marriott and Selwyn (2004) studied the use of information and communications technology (ICT) by undergraduate students and their views regarding Internet use in accounting programs at two UK universities. The study used a descriptive and qualitative research design. Primary data was used whereby questionnaires were used to assess student computer technology and Internet use in the educational program. They were administered to all accounting students in 1998/1999 and 2000/2001, allowing the researchers to match a subset of 98 students' responses at the beginning and end of their program. Seventy-seven students were also interviewed in discussion groups to investigate their attitudes regarding courses offered over the Internet. Questionnaire results showed a significant increase in internet and email usage over the period of the study; use of ICT differed depending on the institution studied; and males reported higher word processing, spreadsheet, general ledger, and overall computer use. The results of the qualitative interviews indicated that students at these two universities value the social interaction and the communication skills they acquire from the classroom environment.

DeLange, Suwardy and Mavondo (2003) sought to find out the importance of using Web CT by accounting students. The purpose of the study was to examine the relationship between attributes of a virtual learning environment (VLE) and student motivation. The study used a descriptive research design. Primary data was collected through surveying 292 on-campus undergraduate students enrolled in an introductory accounting class at a large Australian university regarding the use of WebCT. The students' survey responses to an overall evaluation were used as a surrogate for motivation. Regression results showed that student satisfaction with VLE was significantly associated with providing lecture notes online, use of a bulletin board, online assessment, and other tools such as chat or video.

Gardner, Milne, Stringer, and Whiting (2005) conducted a study of communication apprehension in New Zealand accounting majors. Communication apprehension addresses the anxiety associated with communication, and includes apprehension about both oral and written communication. The study used a descriptive research design. They surveyed a cross-section of undergraduate accounting students regarding oral communication apprehension (usable $n=434,70 \%$ 
response rate) and written communication apprehension (usable $n=430,70 \%$ response rate). Factor and reliability analysis revealed that exposure to communication demands in the curriculum does not exacerbate communication apprehension in accounting students.

\subsection{Problem Solving Competence and Performance}

Accounting professionals are often asked to discern the true nature of a situation and then determine the principles and techniques needed to solve problems or make judgements. Thus, individuals entering the accounting profession should display effective problem solving and decision-making skills, good insight, and judgement, as well as innovative and creative thinking (American Association of Certified Public Accountants, 2005). Accounting professionals must be able to work with others to accomplish objectives. This requires them to act as valuable business partners within organisations and markets and work in teams to provide business solutions. Thus, individuals entering the accounting profession should demonstrate an ability to work productively with individuals in diversity of roles and with varying interests in the outcome. Individuals entering the accounting profession should be able to effectively lead in appropriate circumstances. This involves acquiring the skills needs to influence, inspire, and motivate individuals and groups to achieve results (American Association of Certified Public Accountants, 2005).

Wolk and Cates (2004) used Adaptor Innovator (A_I) theory to study differences between problem solving styles of accounting students and other business majors and minors in an effort to determine whether accounting majors possess the innovative problem solving styles demanded by the profession. Adaptors work best with structure while innovators prefer unstructured situations. The instrument was administered to 157 junior and senior level students at a single university (39 accounting majors, 63 business majors, and 55 business minors). Differences between accounting and business majors/ minors were found with the former more likely to be adaptors than the latter.

Perels, Gurtler and Schmitz (2005) examined the effects of different trainings on the acquisition of mathematical problem-solving and self-regulation was studied with 249 eighth-graders. The study was conducted with 4 different trainings in German grammar schools. Each training consisted of six 90-min sessions on a weekly basis. The results confirm that it is possible to improve mathematical problem-solving and self-regulation competence through this kind of short training. The evaluation shows that the combination of self-regulatory and problem-solving strategies leads to the best effects for the improvement of self-regulatory competences. Furthermore, it is possible to improve problem-solving by practicing problem-solving and self-regulatory strategies or a combination of both.

Arunachalam, Sweeney and Kurtenbach (1997) investigated the relationship between Kirtons adaptor innovative (KAI) cognitive style of problem-solving, the structure inherent in an accounting task and student performance. In one experiment AIS students $(n=75)$ performed a structured accounting task (a case with detailed instructions and a predetermined solution). In another experiment intermediate accounting students ( $n=52)$ performed an unstructured task (created a fictitious company and fictitious transactions). Of the 145 students for whom a KAI score was available 104 (72\%) were classified as adaptors and $48(21 \%)$ as innovators. Further, $70 \%$ of the students attempting the structured task were adaptors, as were $74 \%$ of the students attempting the unstructured task. The authors found that as expected, students classified as innovators outperformed those classified as adaptors on the unstructured task. However, no statistically significant difference in performance was found between innovators and adaptors on the structured task.

Montano, Cardoso, and Joyce (2004) sought to find out other factors that could add value to accounting studies. The study used a case study research design. They used two different case-teaching methods in a financial statement analysis class at a Spanish university to investigate the effect of using decision-oriented complex cases to improve nontechnical skills. The experimental group $(n=48)$ used more complex, decision-oriented cases versus a control group $(n=60)$ that used shorter, more process-oriented cases. Both groups had the same teacher, tutor, and final exam. Results from a questionnaire and class performance indicated that average grades did not differ between the two groups, but that the grade distributions did differ, with the control group's performance more polarised. Student perceptions were reported to help understand differences between the two groups. In addition, the results showed that there is an increased importance of nontechnical skills (communication and problem-solving skills) for those entering the accounting profession.

\subsection{Personal and Interpersonal Competence and Performance}

Purcell and Quinn (1996) suggested that students have been criticised for having unrealistic expectations of the types of responsibilities they may be given and consequently the types of skills they will be expected to exercise on entering the industry. At the same time, the industry tends to discount a student's formal qualification on the grounds of lack of 
experience and frequently we hear the complaint that students are overqualified but under experienced for even entrylevel management positions (Raybouldand Wilkins, 2005).

According to Gail (nd), interpreting changing levels of personal attributes while improving effective teaching behaviors can be one goal of teacher education programs. The researcher indicates that education majors often begin their teacher education programs with high levels of self-efficacy. Students' abilities frequently decline as pre-service teachers' progress through their curriculum and make the transition to in-service teaching. A slight decline in these levels can be interpreted as a learner teacher's greater understanding of the complexity of the teaching process.

Kimmel (1995) presented a framework for integrating critical thinking into the accounting curriculum. The framework defined the basic elements of critical thinking. Analysis was done by breaking critical thinking into identifiable components. This allowed evaluation of what aspects of the critical thinking process are adequately addressed by the current curriculum and which will need additional emphasis. Results showed that implementation of the framework with consideration given to the implications of the stages of college student intellectual development would improve their performance.

A study by Hewlett, Davidson, Nakazono, Baumeister, Carreon and Freed (2007) pointed out that the use of students' self-perception to measure their competence has limitations. The researcher's analysis reveals compelling factors for informing the development and delivery of cultural curricula in dental schools. Furthermore, the researchers expected to have planned analyses of faculty survey and qualitative data from the Pipeline sites that will enable a more focused examination of these factors and, when considered together with the student survey data, mitigate its inherent limitations.

Gracia and Jenkins (2003) attempted to identify the factors that cause differences in academic performance among Welsh undergraduate accounting students enrolled in their second and final years of study (three-year program). The study used a descriptive research design. Primary data was used for analysis. The data were collected from 102 secondyear students and 118 final-year students. Sources of the data included the Student Administration System, a voluntary IQ test to the students, a voluntary questionnaire was administered to the students to gather attitudinal data, and classroom behavior that was observed to measure the responsibility that the students demonstrated. The research found that certain groups of students outperform their cohort as follows: second-year female students outperformed secondyear males; final-year students who were attending their first-choice university outperformed those students not at their first-choice university; students in both years with higher past-year GPAs outperformed students with lower past-year GPAs; and students who demonstrated more commitment toward their studies outperformed students who did not.

Lowry and Flohr (2005) state that people on the other hand are best able to judge their own level of competence as they are the ones who are going through the process of learning, which is part of the curriculum. Faculty members are therefore only able to judge certain generic and fundamental skills of the students and definitely not the specific skills and their appropriateness in career competence as taught in the curriculum (Lowry and Flohr, 2005). Thus, curriculum evaluation in education should involve both the perspectives of the students, and the knowledge of the providers, who are experts in both industry and academics (English and Kaufman, 1975).

Several needs assessment studies were also undertaken to identify discrepancies between student competences. An example would be Knutson and Patton's (1992) survey of 251 juniors and seniors of Michigan State University in the United States about their expectations and career preparedness. Their findings show that students felt positive about the different abilities and skills they required for a successful hospitality career but only 1 in 5 students believed that they were prepared for the future.

\subsection{Information Technology Competence and Performance}

Wessels, (2004) sought to find out the relationship between information technology and the education of professional accountants. The objective of the study was to investigate the extent of the changing environment in which professional accountants will need to operate in future, focusing specifically on information technology. The study used an explanatory research design. Secondary data from historical records in the evolution of the accountancy profession were used. An analysis of the envisaged changes in the business environment was carried out. Results showed that the future role of the professional accountant would change dramatically, from traditionally a collector and disseminator of information to in future an interpreter and strategic decision maker. These changes would be mainly due to the rapid development of information technology, which has rendered the preparation and dissemination of information inexpensive.

Grande, Estébanez and Colomina (2011) aimed to study the empirical evidence, at measuring the relationship between the use of the Accounting Information Systems (AIS) by the Small and Medium Sized Enterprises (SMEs) in Spain, and firms' improved performance indicators and productivity. This empirical study was based on a survey carried 
out among small and medium-sized firms to ascertain the extent to which the development and implementation of accounting information systems had taken place, and subsequently an analysis was made as to how much this introduction may impact on improvement in outcome indicators and productivity. Results found that there is a positive relationship among the SMEs that use AIS for fiscal and bank management and better performance measures. This research provides value added in accounting literature given the scarcity of works dealing with the relationship between the application and use of AIS and performance and productivity indicators in SMEs in Spain.

Greenstein and McKee (2004) sought to determine the self-reported IT knowledge levels of accountants and perceptions about the best places to learn IT skills in America. A literature review conducted resulted in the identification of 36 critical information technologies. The researchers surveyed 1000 accounting information systems and auditing academics and 1000 audit practitioners. After conducting factor analysis, they found a relatively low level of knowledge of e-commerce and advanced technologies and audit automation constructs among both educators and practitioners, but found a relatively high level of knowledge of office automation and accounting firm office automation constructs.

Ismail and King (2005) discovered a positive association between accounting management information system alignment and SME strategy and performance measures. In the Spanish case, Gil (2004) posits an indirect relationship between AIS and firms' performance via the varying strategies that may be adopted by companies. Despite some authors who postulate that the direction of the cause-effect relationship is only that companies achieve a high performance when they can afford the implementation of certain technological developments (Damanpour \& Gopalakrishnan, 2001), others indicate that firm performance drops just after the implementation, taking several years to realize the benefits from IT adoptions (Wah, 2000). There are several research works, which, in the widest sense, have studied relationships between performance indicators and IT, and how IT impacts on firm performance with inconclusive results.

Wessels, (2005) sought to identify which information and communication technology (ICT) skills are critical for professional accountants who wish to be competent in the current and future working environment. A literature review was conducted of research by various professional accountancy bodies and other stakeholders to determine the competence that future professional accountants will need and the impact of the changing environment on the curricula set by professional accounting bodies. The study used an explanatory research design. The study used secondary data from reliable sources. Results showed that ICT skills were required by professional accountants in order to be competent in today's work environment.

Hamdan (2011) investigated the impact of information accounting system development life cycle on its effectiveness and critical success factors. A balanced scorecard was used to evaluate the accounting information system's effectiveness. The card included all the necessary requirements for the accounting information system. The dimensions included tangibility, reliability, responsiveness and empathy. The results indicated that the accounting information system should be based on satisfaction and usage measures as supportive for decision making.

\subsection{Competence in Modern Accounting Techniques and Performance}

Kanellou and Spathis (2011) confirmed that there is a reduction in the time and frequency of preparation of financial statements; monthly, quarterly and annual financial statements after the adoption of modern accounting techniques. Similarly, Salehi et al. (2010) confirmed in their study that sophisticated AIS improves accounting performance. This performance is reflected in the adoption of new accounting techniques. Ngongang (2005) validated that there is a statistically significant relationship between accounting practices and performance expressed in terms of autonomy, turnover evolution and reduced cost levels. In addition, and in a context of advanced information technologies, Rom (2008) proposed that these technologies influence the business processes, which in turn influence the business performance. These processes will be represented by the accounting practices adopted by firms.

Conradie (2012) assessed how hospitality training programs helps students to prepare for their future careers within the hospitality sector. The case study was the South Africa's international hotel school which contributes to preparation of students from their own perspectives. The study recommended the international hotel school needs to review the hotel and restaurant accounting course and the experiential learning components. An additional recommendation also was made to the lecturers who ought to receive training on the implementation of more interactive course content delivery methods. Knutson and Patton (1992) argue that educators are in a better position to evaluate the curriculum as they are able to interpret both sides of the coin, namely the academic side and the industry side. Swanger and Gursay (2007) however, mention that faculty members may, in addition, lack specific knowledge of the curriculum outside the scope of their teaching emphasis, and thus might not accurately judge the competence of students in their own areas of expertise. More so, the level of the faculty members' judgement within their own area, may be highly biased, and may not be a true reflection of student preparedness, even though they are the ones who are delivering the learning 
to the students.

Nelson, Ratliff, Steinhoff and Mitchell (2003) studied whether the formal teaching of logic (valid and invalid argument forms) to auditing students would reduce audit judgement errors. The study used a descriptive research design. Primary data was used whereby a questionnaire with 20 scenarios calling for a logical conclusion was presented to 19 undergraduate auditing students with seven 75-minutes modules on logic, 15 undergraduate auditing students with two class periods devoted to logic instruction, 13 graduate students in accounting with no instruction in logic and 18 experienced auditors. Results showed that students trained in logic outperformed those without training.

Tan, Fowler and Hawkes (2004) surveyed educators and practitioners to ascertain the management accounting topics/techniques and skills/characteristics considered important for New Zealand graduates pursuing a career in management accounting. The study used an explanatory research design. Secondary data was used whereby practitioners considered all topics studied to be important with cash flow management, operational budgeting, variance analysis, and performance evaluation ranking as the top four topics. Educators considered all topics except computer systems-ERP to be important, with behavioral implications, activity-based costing, performance evaluation, and product costing ranked as the top four. Results showed that problem solving, thinking, listening, and quantitative skills were ranked among the top four skills by both groups. The top four characteristics for both groups included common sense, professional attitude, intellectual capacity, and motivation. T-tests for differences in mean importance for the two groups and sensitivity analysis for differences due to size and industry classification were reported.

Stuart (2004) examined whether immediate feedback has an effect on student performance. The study used a descriptive research design. Three groups of randomly-assigned auditing students in Singapore participated: 27 students in the control group were given no training; 29 students in treatment group 1 received one hour of training in analytical procedures without feedback; and 29 students in treatment group 2 received training and feedback. Training included working through multiple-choice questions about analytical procedures, and both treatment groups were given the correct answer immediately after responding to the question. Treatment group 2 was also given an explanation of the correct answer (feedback). After training, or immediately for the control group, each student answered several multiple-choice questions and worked a trend analysis problem and a ratio problem. ANOVA results indicated that the level of training affected performance on the two problems but not on the multiple-choice questions. In pair wise comparisons of problem scores, treatment 2 group outperformed the treatment 1 and control groups, but no difference was found between the treatment 1 and control groups, suggesting that feedback improved performance significantly, while training alone did not.

\section{Research Gaps}

This section provides a review of the research gaps identified from the literature above;

\subsection{Gaps on the Objectives and Expected Findings}

The study identified some research gaps from the literature which are discussed herein. The literature results fail to find any strong association between levels of communication apprehension and students' abilities to advance in their studies or average levels of academic performance. Carrell and Willmington (1998) report that no relationship was found between self-reports of communication competence and ratings of communication competence. Additionally, they also found no relationship between self-reports of communication apprehension and observer ratings of communication competence. This reveals a gap as far as objectives/aims are concerned since the objective of the current study is to establish the relationship between communication competence and performance. Another gap exists due to lack of conclusiveness and consistency of findings. Findings from Carrell and Willmington (1998) are contrary to the expected findings/ hypothetical arguments of the current paper, which predicts a positive relationship between communication competence and performance. The educational and philosophical basis is that students learn by doing, by an experiential process, and particularly in regard to the development of broader generic skills associated with leadership, communication, and interpersonal behavior.

Clare, Gardner, Stringer and Rosalind (2003) investigated the impacts of curriculum on students' levels of communication apprehension. The results from this study show that students in their final year of study who are exposed to greater communication demands, do not on average have higher levels of communication apprehension than their peers in earlier studies. As identified, the objectives were slightly different from the current paper since the current paper attempts to establish a relationship between communication competence and performance.

Perels, Gurtler and Schmitz (2005) examined the effects of different trainings on the acquisition of mathematical problem-solving and self-regulation by focusing on 249 eighth-graders. The researchers' article investigated the 
possibility to foster self-regulatory competence relevant for school-based learning and academic achievement. It concentrated on the training of self-regulatory competence at eighth-grade students, in German grammar schools and concluded that it is possible to improve mathematical problem-solving and self-regulation competence through this kind of short training. The study leaves a gap because its objectives were slightly different from the current study. The current study attempts to establish the effect of problem solving competence on performance while that of Perels, Gurtler and Schmitz (2005) focused on effects of different trainings on acquisition of mathematical problem solving and self regulation competencies.

\subsection{Methodology Gaps}

Hamdan (2011) used a balance scorecard to evaluate the accounting information system effectiveness. The study left a gap with regard to the research instrument used given that the current study opts to adopt questionnaires to measure the effects of technology competence of the accounting profession. Hewlett, Davidson, Nakazono, Baumeister, Carreon and Freed (2007) study objective was to measure students' self-perception on their competence, used qualitative data while the current research hopes to gather quantitative data. Qualitative data involves a face to face interview with the respondents, especially if primary data was used. Face to face interview limits respondents' confidence on the researcher thus resulting in information bias.

\subsection{Gaps on the Scope and Geographical Context}

A study by Hewlett, Davidson, Nakazono, Baumeister, Carreon and Freed (2007) studied students' self-perception to measure their competence in dental schools. The scope of the study was in a different setting, that is, dental schools while the current research lies within the accounting profession. Perels, Gurtler and Schmitz (2005) examined the effects of different trainings on the acquisition of mathematical problem-solving and self-regulation by focusing on 249 eighthgraders. The results confirmed that it is possible to improve mathematical problem-solving and self-regulation competence through this kind of short training. The finding of this study leaves a gap, because the targeted population consisted of eighth graders in German schools, and the current paper focuses on accountants in practice.

Grande, Estébanez and Colomina (2011) aimed to study the empirical evidence, at measuring the relationship between the use of the Accounting Information Systems (AIS) by the Small and Medium Sized Enterprises (SMEs) in Spain, and firms' improved performance. Their findings indicate that AIS positively impacts performance. As much as the findings of the study support the objective of the current review, it was a finding from another country (Spain), whose environment cannot be assumed to be the same with South Africa. Similarly, a gap was also identified in Ismail and King's (2005) study, which also discovered a positive association between accounting management information system, Case of Spanish companies. The regulatory and industry environment faced by Spanish companies may differ with that of South African companies.

\section{Conclusion and Proposed Model for Further Study}

Analysis of the curriculum related competence of cost accountants is an area that has not been deeply explored, which can be evidenced from the scarce empirical literature and numerous research gaps. The identified gaps from the literature review open an opportunity for further research.

\section{Policy Implication}

This paper provides implications for both policy and practice. The accounting bodies should collaborate with universities and advise them on the skills and competencies required by accountants. In addition, the accounting bodies should organize frequent seminars and workshops to impart the necessary competencies.

The universities should revise their curriculum to enhance the dissemination of competencies in communication, information technology, problem solving, personal, interpersonal, and modern accounting techniques. In addition, they should form working relationship with the industry as an effort to enhance internship opportunities for students taking cost accounting.

The government should offer incentives to industry in form of tax waivers to encourage industry members to create internship opportunities for cost accounting students. The savings from tax waivers can be used by industry to fund internship programmes. 


\section{References}

American Institute of Certified Public Accountants (2005). Personal Competences. New York.

Armitage, A., Bryant, R., Dunnill, R., Hayes, D., Hudson, A., Kent, J., Lawes, S. \&Remwick, M. (2003). Teaching and Training PostCompulsory Education, 2nd ed. Buckingham.

Arora, A. (2010). Relationship among Curriculum Coverage, Teacher Preparedness, and Student Achievement in TIMS.Curriculum Coverage and Teacher Preparedness. TIMSS \& PIRLS International Study Center, Boston College.

Arunachalam, V., J. Sweeney, \&Kurtenbach J. (1997). The Relationship Between Cognitive Problem-Solving Style and Task Structure in Affecting Student Performance, The Accounting Educators' Journal, Vol.IX, No.1,1-13.

Burns, J. \&Vaivio, J. (2001).Management Accounting Change.Management Accounting Research, 12(4), 389-402

Carrell, J. \&Willmington, C. (1998). The Relationship between Self-Report Measures of Communication Apprehension and Trained Observers: Ratings of Communication Competence, Communication Reports, 11, 87-95.

Clare, T., Gardner, J. M., Stringer, P.C. \& Rosalind, H. W. (2003).Oral and Written Communication Apprehension in Accounting Students.Curriculum Impacts and Impacts on Academic Performance. Dunedin, New Zealand

Conradie, R. (2012). Student Evaluation of Career Readiness after Completing the Hospitality Management Curriculum at the International Hotel School.Unpublished Project.University of South Africa.

Damanpour, F. \&Gopalakrishnan, S. (2001). The dynamics of the adoption of product and process innovations in organizations. Journal of Management Studies, 38 (1), 45-65.

De Villiers, R. (2010). The Incorporation of Soft Skills into Accounting Curricula: Preparing Accounting Graduates for their Unpredictable Futures.Faculty of Business and Law, AUT University, Auckland, New Zealand.

DeLange, P., Suwardy, T. \&Mavondo, F. (2003).Integrating a Virtual Learning Environment into an Introductory Accounting Course: Determinants of Student Motivation.Accounting Education, 12(1), 1-14. Educators Journal,8 (Spring) 1-13.

English, F. \& Kaufman, R. (1975).Needs Assessment: A Focus for Curriculum Development.Washington D.C., VA: Association for Supervision \& Curriculum Development.

Flower, J. (1999).In the Mush.Physician Executive,25 (1), 64-6.

Gail, V. B. (nd).Self-Efficacy and Teaching Effectiveness. University of South Carolina

Gardner, T., Milne, J., Stringer, P. \& Whiting, H. (2005).Oral and Written Communication Apprehension in Accounting Students: Curriculum Impacts and Impacts on Academic Performance.Accounting Education, 14(3), 313-336.

Gil, D. (2004). The Role of Sophisticated Accounting System in Strategy Management. The International Journal of Digital Accounting Research, vol. 4, n. 8: 125-144.

Gracia, L. \& Jenkins, E. (2003).A Quantitative Exploration of Student Performance on an Undergraduate Accounting Programme of Study.Accounting Education, 12(1), 15-32.

Grande,E., Estébanez, R. \&Colomina, C. (2011). The impact of Accounting Information Systems (AIS) on performance measures: empirical evidence in Spanish SMEs. The International Journal of Digital Accounting Research Vol. 11

Greenstein, M. \& McKee, T. (2004). Assurance Practitioners' and Educators' Self Perceived IT Knowledge Level: An Empirical Assessment. International Journal of Accounting Information Systems, 5:213-243.

Hassall, T., Joyce, J., Ottewill, R., Arquero, J., \&Donoso, J. (2000). Communication apprehension in UK and Spanish business and accounting students, Education \& Training, 42(2-3), pp. 93-100

Hamdan, M. W. (2011). The Impact of Accounting Information Systems (AIS) Development Life Cycle on its Effectiveness and Critical Success Factors. European Scientific Journal, 8 (6).

Hewlett, N., Edmond, R., Davidson, P., Pamela, L., Nakazono, T., Baumeister, J., Carreon, C. \& Freed, A. (2007). Revisions to Dental School Curricula: Effects of the Pipeline Program Journal of Dental Education; 73(2).

Ismail, N.A. \& King, M. (2005).Firm Performance and AIS alignment in Malaysian SME's. International Journal of Accounting Information Systems, 6 (4) 241-259.

Kanellou, A. \&Spathis, C. (2011).Accounting Benefits and Satisfaction in an ERP Environment. Paper Presented at the $8^{\text {th }}$ International Conference ICESAL, Enterprise Systems, Accounting and Logistics, Greece.

Kimmel, P. (1995). A Framework for Incorporating Critical Thinking into Accounting Education.University of Wisconsin-Milwaukee.

Knutson, B. \& Patton, M. (1992). How Prepared am I to Succeed in the Hospitality Industry? What the Students are Telling us. Journal ofHospitality \& TourismEducator, 4(3).

Lowry, L.L. \&Flohr, J.K. (2005). No student left behind: A longitudinal Assessment of the Competency-Based Framework used to Facilitate Learning in a Capstone Tourism Course. Journal of Hospitality \& Tourism Education, 17 (4).

Marriott, N., Marriott, P. \& Selwyn, N. (2004).Accounting Undergraduates' Changing use of ICT and their Views on Using the Internet in Higher Education: A Research Note.Accounting Education, 13(Suppl. 1), 117-130.

Montano, L., Cardoso, J. \& Joyce, J. (2004). Skills Development, Motivation and Learning in Financial Statement Analysis: An Evaluation of Alternative Types of Case Studies. Accounting Education, 13(2), 191-212.

Neary, M. (2002).Curriculum Studies in Post-compulsary and Adult Education: A Teacher's Study Guide. Chelterham: Nelson Thornes Ltd.

Nelson, T., Ratliff, L., Steinhoff, G. \& Mitchell, J. (2003). Teaching Logic to Auditing Students: Can Training in Logic Reduce Audit Judgement Errors? Journal of Accounting Education, 21(3), 215-237.

Opt, S. \&Loffredo. D. (2000).Rethinking Communication Apprehension: A Myers-Briggs Perspective. The Journal of Psychology, 134(5), 
556-570.

Perels, F. Gurtler, T. \& Schmitz, B. (2005).Training of Self-Regulatory and Problem-Solving competence.Elsevier, 15, 123-139.

Process Coaching Center (2001). The Four Stages of Learning.Ukiah, CA.

Pucell, K. \& Quinn, J. (1996). Exploring the Education Employment Equation in Hospitality Management: A Comparison of Graduates and HNDs. International Journalof Hospitality Management, 15(1), 51-68.

Raybould, M. \& Wilkins, H.C. (2005). Over Qualified and Under Experienced: Turning Graduates into Hospitality Managers. International Journal of ContemporaryHospitality Management.17 (3).

Rom, A. (2008).Management Accounting and Integrated Information Systems: How to Exploit the Potential for Management Accounting of Information Technology.Unpublished PhD. Copenhagen Business School.

Salehi, M., Rostami, V. \&Mogadam, A. (2010).Usefulness of Accounting Information System in Emerging Economy: Empirical Evidence of Iran. International Journal of Economics and Finance, 2 (2).

Scapens, R. W. (2006). Understanding Management Accounting Practices: A Personal Journey. The British Accounting Review, 38, 130.

Shapiro, D.L., Kirkman, B.L. \& Courtney, H.G. (2007) Perceived Causes and Solutions of the Translation Problem in Management Research. Academy of Management Journal, 5092, 249-266.

Sharma, U., Lawrence, S. \& Lowe, A. (2010).Institutional Contradiction and Management Control Innovation: A Field Study of Total Quality Management Practices in a Privatized Telecommunication Company.Management Accounting Research, 21(4), $251-264$.

Stuart, I. (2004). The Impact of Immediate Feedback on Student Performance: An Exploratory Study in Singapore.Global Perspectives on Accounting Education, 1, 1-15.

Tan, L. M., Fowler, M. \& Hawkes, L. (2004). Management Accounting Curricula: Striking a Balance Between the Views of Education and Practitioners. Accounting Education. An International Journal, 13(1), 51-67.

Van Helden, G. J. \&Northcott, D. (2010). Examining the Practical Relevance of Public Sector Management Accounting Research.Financial Accountability \& Management, 26(2), 213- 240.

Wah, L. (2000). Give ERP a chance. Management Review, 89 (3) 20-24.

Wessels, P. (2004). Information Technology and the Education of Professional Accountants.Department of Accounting, University of Stellenbosch.

Wessels, P. (2005). Critical Information and Communication Technology (ICT) Skills for Professional Accountants. Department of Accountancy, University of Stellenbosch.

Wolk, C. \& Cates, A. (2004).Problem-solving Styles of Accounting Students. Are Expectations of Innovation Reasonable? Journal of Accounting Education, 01 (Fall) 158-171. 